\title{
Mentors' Perceptions of Teacher Practice: A Case Study of the School of Vocational Teacher Education
}

\author{
Pirjo-Liisa Lehtelä, Iiris Happo \\ Oulu University of Applied Sciences, Finland
}

\begin{abstract}
Mentoring has emerged as an essential and effective process for developing teacher practice. The holistic student-centred guidance model is utilised to define the mentors' roles and inputs in the teacher practice mentoring process. The purpose of this article is to describe mentors' perceptions of mentoring teacher students in teacher practice at the School of Vocational Teacher Education in Oulu, Finland. The material for the development project was collected by conducting an inquiry at the beginning of mentors' guidance training. The study participants included 21 mentors from different vocational schools. In the mentoring process, the interaction and cooperation between mentor and mentee plays an essential role. Mentors' perceptions of their role in mentoring focus mainly on educational guidance and personal guidance. According to the findings, more attention could be focused on mentoring teacher students' vocational development during teacher practice. The results can be used in developing the mentors' guidance training.
\end{abstract}

\section{Introduction}

Mentoring has emerged as an essential and effective process for developing teacher practice [1]. The teacher practice mentoring process has been studied from different viewpoints; the objects of the studies have mainly been primary and secondary school teacher students. Vocational teacher students' mentoring processes have also been studied, but less than other educational degrees. The purpose of this article, therefore, is to describe the mentors' perceptions of mentoring teacher students in teacher practice at the School of Vocational Teacher Education in Oulu, Finland.

In the School of Vocational Teacher Education, the purpose of teacher practice is to provide the students with an opportunity to apply their pedagogical knowledge and skills in practice. The aim is to enable the student to design, carry out and evaluate the teaching methods of his/her own sector and to cooperate with other parties and students in matters relating to teacher practice. One of the additional aims is that the student will be able to understand his/her role in the larger scope of the profession and in the extended operational environment of the school. An important goal is to learn how to develop and advance one's competence. In teacher practice (11 ECTS credits) the teacher student has two supervisors: a tutor from the School of Vocational Teacher Education and a mentor from the vocational school where the teacher practice is carried out. The mentor from the vocational school is pedagogically qualified and he/she is a teacher in the same subject area. The tutor from the School of Vocational Teacher Education specialises in the pedagogical perspective.

The holistic student-centred guidance model by van Esbroeck and Watts [2] considers counselling to be a common shared task between all actors at institutions (schools). In this study, the holistic student-centred guidance model is utilised to define the mentors' roles and inputs in the teacher practice mentoring process (Figure 1).

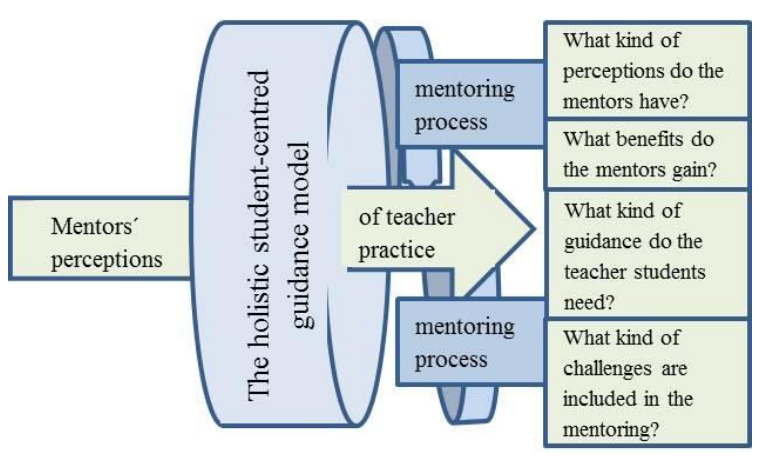

Figure 1. Framework of the study

In this article, we begin briefly by outlining the aspects of mentoring, then we introduce the holistic student-centred guidance model. At the end of the article, we introduce the findings and make some conclusions.

\section{Theoretical background}

\subsection{Aspects of mentoring}

Historically, a mentor has been used to denote a wise and trusted guide or adviser [3]. Hobson et al. [1] defines mentoring as a one-to-one support of a novice or less experienced practitioner (mentee) by a more experienced (mentor). 
According to Murray [4], the action is mentoring if the following aspects can be taken in to count:

- the mentee and the mentor have confidential discussions;

- the focus is on the mentee's and mentor's reciprocal and personal development;

- $\quad$ they meet regularly;

- they deal with practical issues more than theoretical issues in accordance with the mentee's interests [4].

In addition to the above-mentioned structuring, mentoring also consists of a contract between the mentee and the mentor. The institution usually is the third party of the contract. All these aspects are realised in the teacher practice mentoring process at the School of Vocational Teacher Education.

A mentor can play a number of potential roles and corresponding functions, as follows:

- mentor as a model: functions to inspire and demonstrate;

- mentor as an acculturator: functions to help familiarise the particular professional culture;

- mentor as a sponsor: functions to introduce the mentee to the people in the central and significant position;

- mentor as a supporter: functions to provide the mentee with the possibility of sharing and analysing their feelings and experiences;

- mentor as an educator: functions to guide and create opportunities for the mentee's professional learning [3].

The mentor's roles and functions also include supporting the mentee's psychological well-being and taking the social aspects of the mentoring process into consideration. For example Kram [5] stated two basic mentoring tasks: career functions and psychosocial functions. Career functions are the aspects of a relationship that primarily enhance career advancement, for example sponsorship and challenging assignments. Psychosocial functions include role modelling, enhancing the sense of competence, clarifying identity and friendship. [5] These basic functions work well in the mentoring relationship at our school. One of the aims is that the mentee in the teacher practice will be able to understand his/her role in the larger scope of the profession and in the extended operational environment of the schools. An important goal is also to learn how to develop and advance one's competence. It is crucial to recognise that mentoring can have a variety of purposes and goals and can take place at different stages of the mentee's professional development [3].

\subsection{Teacher practice mentoring in the School of Vocational Teacher Education}

In the School of Vocational Teacher Education the teacher practice mentors also have to consider the principles of mentoring an adult. At the School of Vocational Teacher Education in Oulu, the average age of teacher students is 40 years. The teacher students lead a rather typical adult life, which means dividing their time between family, work life and studies. The principles of adult learning should be considered in the mentoring process. [6] The essential question is how to define the mentors' roles and inputs in the teacher practice mentoring process. The holistic student-centred guidance model can be utilised for this process.

\subsection{The holistic student-centred guidance model}

In the holistic student-centred guidance model, the student is the focus (Figure 2). To form the whole picture of the student's support, it is essential to define the different roles and inputs of the different actors. The model contains three areas of student support: 1) personal guidance, 2) educational guidance and 3) career guidance. Personal guidance denotes the support of the student's personal and social issues, which positively affects the development of the person. Educational guidance, however, includes supporting the student in his/her educational choices and supporting the student's progress in his/her studies. Career guidance consists of supporting the student's occupational choices and his/her placement into occupations and work roles. These three areas are not seen as being separate; rather, they overlap. [2]

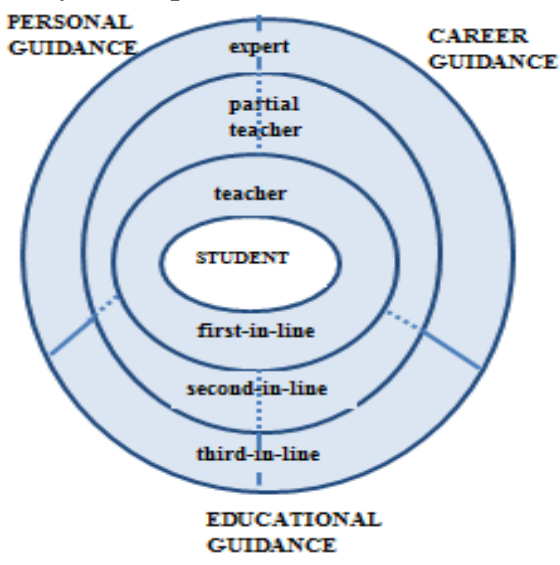

\section{Figure 2. The holistic student-centred guidance model [2]}

In an educational environment, different types of actors play a role in developmental support. The key question is: Who is doing what? In the model, a 
three-in-line approach can be elaborated upon (Figure 2). First-in-line easily covers accessible guidance support. At this level, the staff in question is teachers who have been trained to develop awareness for sensing problems rather than solving them. The guidance support is seen as a part of a formal teaching function. They are not, however, specialised in any particular area of guidance. The first-in-line-staff also consists of different tutors and mentors. In the second-in-line, the guidance system is also linked to the formal teaching function, but at this level there is some degree of specialisation. The staff at this level consists of internal specialists who are involved in guidance to solve and prevent problems. They are involved specifically in individual guidance. The staff at this level contains counsellors and student office workers. The third-inlevel, however, covers external specialist who are not necessarily involved in the teaching process. They can be experts in some particular sector of guidance, but their main tasks are differentiated diagnosis, remediation and support to counsellors at the earlier levels. At this level the staff contains, for example, school study psychologists, study pastors and school health nurses. The workers in the employment office, mental health clinic and the specialists in career and professional guidance are also involved to guide staff at this level.

In the School of Vocational Teacher Education in Oulu, everyone on the teaching staff is involved in the first-in-level guidance. The mentors in teacher practice from different vocational schools can also be seen as a part of this level of guidance. In the School of Vocational Teacher Education, the study office workers and counsellors are involved in the secondin-line. The third-in-level covers external specialist who are, for example, workers in the employment office.

Teacher practice mentors are significant partners in cooperation. The mentors' perceptions highlight their roles and inputs in the teacher practice mentoring process and provide valuable knowledge about how to develop both the cooperation between the different parties and the quality of the mentoring process.

\section{Purpose of the study}

In this development project, the holistic studentcentred guidance model is utilised to define the roles and inputs of the different actors. The mentoring process of teacher practice is of special interest.

The purpose of this development project is to describe the mentors' perceptions of mentoring in teacher practice at the School of Vocational Teacher Education in Oulu. The objectives of the development project are to answer the following questions: 1) What kind of perceptions do the mentors have about the teacher practice? 2) What benefits do the mentors gain from the mentoring process? 3) What kind of guidance do the teacher students need? and 4) What kind of challenges are included in the mentoring process?

\section{Methodology and group}

The material for the development project was collected by conducting an inquiry at the beginning of the mentors' guidance training in January 2012. A total of 21 mentors from different vocational schools participated in the study by answering the inquiry questions.

The research uses a qualitative approach and the study can be characterized as a case study. The mentors' open-ended questionnaire was the data collection method that was used.

Categories were constructed for the mentors' open-ended answers in which the mentors described a variety of things. The outcome, which provided a valuable starting point, consisted of a structured summary of the questionnaire materials. Next, the findings are discussed in more detail by presenting the constructed categories with the mentors' citations between the texts (citations for Mentors 1-21).

\section{Findings}

\subsection{Mentors' perceptions of the teacher practice}

The focus of the first study question was to find out what kinds of perceptions the mentors had about the teacher practice. Some of the mentors described the teacher practice by mentioning tasks that the teacher students should carry out during their practice. They seemed to have an assignmentoriented approach to counselling. They mentioned that the teacher practice means counselling the students in developing their lesson plans and guiding them in using the substance competence (subjectmatter knowledge) that they will need during teaching. Here is an example from one mentor's response:

"To help a teacher student in her/his teaching work. Accept her/his teaching materials and lesson plans and give some practical hints. Take care that teaching runs according to the plan. Also ensure that the goals of the curriculum and tasks for the teacher practice will be reached. Also feedback is very important." (Mentor 12)

Furthermore, the mentors described the teacher practice as counselling the teacher students to understand the level of their students' know-how. All these aspects are essential information that the 
teacher students need in order to handle the entire teaching process.

Another interesting perspective was that some of the mentors outlined the teacher practice in terms of the methodological aspects of counselling. They mentioned the following counselling tools as being especially important: listening, discussion, and giving advice. One mentor itemized this as follows:

- "Guide to the educational knowledge

- Discuss experiences

- Support strengths

- Give feedback, help to be aware of those mannerism and teaching habits, which are not useful in teaching action

- Give new professional ideas and teaching methods

- Guide to the networking; introduce to colleagues and give an opportunity to meet new people

- Introduce teachers work (law)" (Mentor 11)

In addition, the mentors thought that teacher practice means counselling the teacher student's professional development. Developing into a teacher is an individual process and each teacher student needs to find his/her own path of development. In this process, the mentors wanted to be supporters as represented in the following quote:

"Mentor's work is to support and counsel a teacher student in her/his teacher practice. It also includes counselling teacher student's professional development process and getting her/him familiar with the educational environment. It is also continuing interaction with teacher student during the teacher practice." (Mentor 6)

According to the descriptions of some of the mentors, the teacher practice mainly consists of interaction and cooperation between the teacher student and the other cooperating partners. The mentors seemed to have an interaction and cooperational approach to counselling:

"It is the interactions between the teacher student and the staff of the School of Vocational Teacher Education." (Mentor 21)

It is interesting to note that one of the mentors considers that part of the process of mentoring teacher practice also involves mentoring how to network. According to the mentors, networking is part and parcel of the teachers' work.

5.1.1. Summary of perceptions of the teacher practice. The mentors' perceptions of the teacher practice focused on the assignments that are included in the teacher practice. Some of the mentors had an assignment-oriented approach to counselling. In light of the findings, the mentors seemed to understand mentoring as mainly being a synonym for teaching. Furthermore, they defined the teacher practice as the interactions and cooperation between the mentee and the mentor. In the same way their perceptions also included methodological aspects, like listening and discussion. According to Kram [5], mentoring is a collaborative relationship between the mentor and the mentee that supports one's career and personal development throughout one's career. However, in our findings it seems that the mentors understood the teacher practice to a lesser extent as counselling the teacher students throughout the entire length of their careers and more as educating and supporting their teacher practice.

\subsection{Mentors' benefits from the mentoring process}

The second study question clarifies the benefits that the mentors gained from the mentoring process. The aim was to provide a basis for understanding the differences in what mentors found useful in the mentoring process. The results found that they identified versatile benefits from the mentoring process.

It seemed that the mentors did not discuss these benefits only from their own perspective; they also looked at the benefits from the mentees' point of view. According to the findings, the most important benefit for the mentors was to be part of the teacher student's developing process. They seemed to derive satisfaction and pride from undertaking the mentor role, as represented in the following comment:

"I want to succeed as a mentor and help the teacher student move forward in their professional field. (Especially in our teaching field, which is rather minor and there are not many teachers.) I also want to help the teacher student to create contacts and network. The mentoring process helps me to refresh and reflect deeply upon the teaching and learning processes. I will get as much as I give from the mentoring process." (Mentor 3)

Another aspect of the mentors' perceptions is that they experienced the importance of the mentee's psychosocial support as being significant. Emotional and psychological support is an important part of the teacher practice, in general. It is helpful in boosting the confidence of the teacher student and, for example, in enabling them to handle difficult and different experiences. One mentor noted:

"It feels important to support the beginning teacher's strengths.” (Mentor 11) 
Furthermore, basic teaching processes, such as planning skills, classroom management skills, and the ability to manage time, are considered to be beneficial to the mentors:

"It is essential to guide the teacher student's lesson plans and how she/he conducts her/his lessons and teaching content." (Mentor 9)

The mentors also emphasised the importance of interacting with their mentees. From participating in the process of mentoring, they had learned to talk to their mentees about teaching and learning. One could say that they had learned together through the mentoring relationship. This could be called a partnership between the mentors and their mentees, which means a conscious commitment to collaboration for both development and learning. This finding is supported by the following quotes from the mentors:

"The interaction between the mentee and the mentor is essential and it is also important that they learn together." (Mentor 10)

\section{“The mentees' enthusiasm is catchy!” (Mentor 16)}

Furthermore, the mentors applied a methodological point of view to describe the benefits of mentoring. They especially emphasised that adequate time is required for their meetings and regular appointments with their mentees:

"It is important to create a good and confidential relationship, then the shared journey can start. Regular meetings are essential. It is also important to allow sufficient time in the mentoring process." (Mentor 14)

The mentoring process was also shown to have an impact on the mentors' learning. The mentors' own development during the mentoring process is a valuable benefit. The mentors reported that they learned new teaching strategies and improved their current teaching strategies; they also reported that they had enhanced their knowledge. Involvement in the mentoring process also helped them identify and analyse their own personality more deeply. The following quote is representative of those responses:

"I also want the mentoring process to benefit my own teaching and growing as a person." (Mentor 6)

5.2.1. Summary of the benefits from the mentoring process. The mentors felt that being a part of the mentees' development process and using their own experience and know-how to help their mentees were positive and significant experiences. Earlier studies have suggested that mentoring is an important and effective process and it is perhaps the best way to support the professional development of teacher students $[3,7]$. According to our findings, it also enhances the professional development of the mentor. Hagger and McIntyre [8] have found that the mentors' satisfaction is related to noticing evidence about how the mentors own behavior impacts the mentees' development.

The mentors also felt enthusiastic about working with their mentees and they generated new ideas about their own teaching work during the mentoring relationship. McCorkel and Tamar [9] and Perunka and Erkkilä [10] have also delineated that the mentoring process provided mentors with opportunities to engage in cooperation, innovate new teaching methods, and acquire new perspectives about student knowledge. It seems that the benefits that the mentors receive from the mentoring process are not dependent upon the culture in which they live. Our findings confirm that. In addition, our findings highlight the valuable possibility that the mentor and the mentee can reflect together and share their thoughts during the teacher practice learning process. Certainly that process provides mentors and mentees with an excellent possibility to learn together. For vocational teachers, who often work alone, the collaborative teaching process provides a supportive environment in which they can become acquainted with one another's teaching style. At its best, the collaborative teaching process allows both the mentor and the mentee to benefit from the healthy exchange of ideas in a setting defined by mutual respect and a shared interest in a topic [11, $12]$.

\subsection{Guidance needs of the teacher student}

The focus in the third study question clarifies the kinds of guidance needs the teacher students have. The guidance needs described by the mentors can be grouped into two distinct categories: needs for carrying out the teaching practice (the implementation of all the sections of the teacher practice) and needs for guiding the teacher students' growth and personal development. In addition to these major findings, some individual matters and concerns also surfaced in the mentors' responses and will be discussed later in this article.

In the first category, the implementation of all the sections of the teacher practice, the focus is on the implementation of the teacher practice. Here, the mentees' guidance needs mainly consist of the ability to handle the entire teaching process.

Due to their lack of experience in the field, the mentees might have difficulty getting familiar with students, understanding them, and dealing with individual differences. However, the mentors know their students and, in general, they are highly experienced in teaching different groups and a 
variety of people. Therefore, the relationship between the mentor and the mentee is not only significant, it is also especially fruitful. This point is illustrated in the following quotes from the mentors:

"For the youth of today, teacher students are frightened by their students and they (teacher students) can't act as an educator." (Mentor 18)

"To understand and accept the diversity of students." (Mentor 19)

"To keep a group of students under a control (group management), what to do in exceptional situations." (Mentor 3)

The mentors also highlighted that they believed that mentees needed support in how to carry out the teaching in the classroom, as well as how to plan functional and stimulating lessons. The teacher students needed to learn situationally-relevant approaches to their subject matter. This means the ability to teach the subject matter in a way that students are able to internalise the material.

During their teacher practice sessions, the students get familiar with the new teaching organization. The mentors in this study thought that the teacher students needed help in adapting to the norms and standards associated with teaching in general, but they also needed help in adapting to the organization where their teaching practice took place. This is addressed in the following comment:

"How to handle practical matters during the teacher practice." (Mentor 14)

The teacher students also had other special guidance needs. The second category, which is discussed next, consists of the mentors' needs for guiding the teacher students' growth and personal development. In the second category, guiding the teacher students' growth as a professional teacher, the mentors outlined the importance of emotional and psychological support. They also emphasised that it is essential to help the mentees identify their strengths. Many times the teacher students are too demanding of themselves. Teaching often takes shape from the teacher's strengths, especially in the beginning of one's teaching career. The following quotes are representative of the mentors' responses:

"To help to understand the pieces of a whole, to understand diverse learners in practice to get guidance for that, to permit themselves to receive support."(Mentor 9)

"To identify one's strengths and weaknesses." (Mentor 2)
"It is important to give feedback from your own actions." (Mentor 3)

The mentors pointed out that the teacher students needed encouragement in order to refresh their teaching. Among the students, that are teacher students, there are also those who already have extensive experience in the field of teaching. However, the expertise of a vocational teacher is apparently versatile and this phenomenon results in different kinds of skills and competences. For the teacher students that have previous teaching experience, the mentors recommended that it is important to provide them with new ideas and to refresh their thinking about teaching and learning. This is represented by the following mentor comment:

"To get fresh ideas and to learn pedagogical
approaches." (Mentor 20)

In general, in the teacher practice the important goal is to develop one's competence and to learn how to advance one's teaching skills in later life.

In addition to the two major findings, individual matters also surfaced from the mentors responses. These are described next. The mentors considered the students' knowledge and skills development to be important during the teacher practice. The mentors are responsible for insuring that the students reach their learning goals and that the curriculum is followed during the teacher practice. Usually, the teacher students already have a good work experience in their teaching field and the teacher students share authentic and current know-how from their working life with the students and with their mentees. This is a productive and educational situation for all of the people involved in this process, as shown in the following mentor response:

"The interaction between the students and the mentee is fruitful and developed all of us (student, mentee, and I)." (Mentor 7)

Some of the mentors did not highlight any counselling needs for the teacher student (two mentors). They mentioned that the teacher student already had a good teaching ability. However, they mentioned that counselling needs are certainly dependent upon the mentee's teaching experience, as noted in the following response:

"It depends on the teacher student; has he/she taught before or is he/she coming from a working life." (Mentor 15)

At the School of Vocational Teacher Education, the teacher students have different experiences with teaching. Some of them have taught already for a 
couple of years or even for several years, and some of them do not have any teaching experience. However, every teacher student has a relevant university or polytechnic degree and a minimum of three years of experience working in a field corresponding to their degree.

5.3.1. Summary of the guidance needs. The guidance needs described by the mentors focused on the implementation of all the sections of the teacher practice, especially how to understand and handle students. In those cases, mentoring is concentrated on the practical implementation of the teacher practice. The study conducted by Happo and Lehtelä [13] noted that, for vocational teacher students, the main concerns are connected to this level of knowledge. The teacher students were worried about the following aspects of teaching: how to plan, organise, and evaluate the learning processes and outcomes [13]. In addition, it is important to help the mentees familiarise with the particular school in which they work and the professional culture of that place. In that point of view, the mentor plays the role of being someone who helps the mentee to acculturate. However, the guidance needs also focus on addressing the personal guidance needs of the teacher student. The mentor needs to increase the mentees' confidence and self-esteem. As Kram [5] has stated, one basic mentoring task is psychosocial function. Our study, which is conducted in the context of vocational teacher education, confirms Kram's [5] views.

\subsection{Challenges in counselling}

In the fourth study question the mentors discussed what kinds of challenges they included in the mentoring process. First, they found it challenging to get to know and to get familiar with the mentee. The teacher practice is based on agreements and cooperation between the mentor and the mentee. They need to discuss in which period the teacher practice will be carried out, when the teacher student will meet the students he/she will be teaching, and other matters such as, for instance, when to observe the mentee's lessons. There are many issues to agree upon and to coordinate. The teacher students at the School of Vocational Teacher Education are adults with their own lives, families, and work responsibilities. Sometimes it is difficult to find a mutual time to discuss these issues, or sometimes the amount of time to do so might be too short. This is represented by the following mentor comments:

"The start!-Once we get to know each other, the pieces just start falling into places." (Mentor 1)

"Issues in the student's personal life may delay or prevent a progress." (Mentor 2)
"When a trainee just wants to complete her/his teacher practice as soon as possible and get rid of compulsory assignments. " (Mentor 11)

The teacher students have different personalities and their counselling needs are diverse. The mentors highlighted the challenges in supporting various people with their different backgrounds and goals. The mentors also experienced challenges to giving feedback to the mentees. The reason for that might be that the mentors do not always have the experience they need to guide the learning process of adult learners. The mentors' challenges focus on how to give supportive and negative feedback, as noted in the following responses:

"You need to find an appropriate way to also give negative feedback, you need to encourage and support the teacher student." (Mentor 13)

"To remember and to remind the teacher student that you cannot always succeed perfectly. No one does and that is normal. The teacher student can regard herself/himself too critically." (Mentor 3)

The mentors also feel pressure about what kind of role model they offer to their mentees, as shown in the following response:

\section{“How to model good teaching.” (Mentor 17)}

Sometimes the mentors might experience inadequacy even at the prospect of their lessons being observed by the mentee.

Furthermore, the mentors were worried about how to obtain resources for the mentoring process. Mentoring takes time and the mentors are willing to engage in the mentoring process. However, in addition to their normal teaching roles the mentors have experienced increasing workloads as a result of their involvement in the mentoring process. The resources they obtain for their mentoring varies from one organisation to another.

5.4.1. Summary of challenges. The challenges highlighted by the mentors focused on how to meet and become familiarised with their mentees. The successful mentoring relationship is based on shared goals and understandings. Some of the mentors also felt insecure about their counselling competence. The mentors in this study experienced challenges in accommodating all their mentees' needs. The skilled mentor has the sensitivity to notice the mentee's guidance needs and the ability to choose suitable counselling methods [14]. The mentors also reflected on being a role model and what kind of model they could offer to their mentees. Furthermore, the mentoring process requires time resources. This was also emphasised as a challenge by the mentors. 
Mentoring is a voluntary task. However, the mentors are interested in and willing to be a mentor for the teacher students at the School of Vocational Teacher Education. As Hudson, Usak, and Savran-Gencer [15] have stated, the mentors are not especially interested in gaining any financial benefit from their role as mentors; rather, they expect to acquire new ideas and refresh their thinking through the mentoring relationship.

\section{Discussion}

Many factors affect the development of vocational teacher students' know-how. Students can affect some of these factors with their own choices, but some of the factors are inevitable and unpredictable, especially the factors that are related to the course of one's life. However, teacher practice is one of the most significant issues during a teacher student's training. Many teacher students obtain their first experience of a teacher's assignments during the teacher practice training. Teacher practice mentors play an especially important role in that process. In order to obtain a general view of the profession, mentoring has emerged as an essential and effective process for developing the know-how of teacher students [1].

According to the holistic student-centred guidance model, both teacher practice mentors and teacher educators are a part of the first level support for teacher students [2]. Therefore, the cooperation between mentors and teacher educators is also significant and a common sense of confidence is important. Mentors and teacher educators have common areas of responsibilities in relation to the teacher students. They both guide the students' tasks and professional growth. Interaction and cooperation are essential and both mentors and teacher educators try to guide teacher students to use different kinds of guiding methods in their own instruction. However, during teacher practice, the teacher student mentoring process is an extremely important part of the teacher students' studies because the implementation of teaching occurs within authentic situations.

In conclusion, overall the mentors' experiences of mentoring vocational teacher students have been positive. The teacher students' mentors found their role to be motivating and inspiring. It is a process in which both the mentors and the teacher students can develop their professional skills.

\section{Conclusions}

The purpose of this article is to describe the mentors' perceptions of mentoring teacher students in teacher practice at the School of Vocational Teacher Education in Oulu. The mentors' perceptions of their role in the mentoring process focused on educational guidance and personal guidance, and career guidance played a minor role. In addition, the teacher students' guidance needs in teacher practice are connected to educational and personal guidance. However, according to the mentors' perceptions, career guidance is considered to be a benefit of the mentoring process. According to the holistic student-centred guidance model, the mentors are a part of the first level of support for teacher students.

In the mentoring process, the interactions and cooperation between the mentor and the mentee play an essential role. Aspects that the mentors consider to be positive in the mentoring process include the possibility of using their experience and developing the mentee's professional skills. The mentors also gain the opportunity to develop their own work skills. The following challenges were identified as being part of the mentoring process: how to meet the mentee, how to obtain the resources needed for the mentoring, and how to handle the limited time resources.

The results can be used to develop mentor guidance training programs. In general, more attention could be focused on mentoring the teacher students' vocational development during teacher practice. The holistic student-centred guidance model can be utilised to define the mentoring roles and to create a conversation about the quality of the mentoring process in teacher practice.

\section{References}

[1] A. J. Hobson, P. Ashby, A. Malderez, and Tomlinson P. D. (2009), 'Mentoring Beginning Teachers: What We Know and What We Don't', Teaching and Teacher Education, 25, pp. 207-216.

[2] R. van Esbroeck and A. G. Watts (1998), 'New Skills for a Holistic Career Guidance Model', International Careers Journal, http://www.careers-journal.com (26 March 2014)

[3] A. J. Hobson and C. Sharp (2005), 'Head to Head: A Systematic Review of the Research Evidence on Mentoring New Head Teachers', School Leadership and Management, 25(1), pp. 25-42.

[4] M. Murray (2001). Beyond the Myths and Magic of Mentoring: How to Facilitate an Effective Mentoring Process. New and revised edition, Josey-Bass: San Francisco.

[5] Kram, K. (1983), 'Phases of the Mentor Relationship', Academy of Management Journal 26(4), pp. 608-625.

[6] A. T. Wong and K. Premkumar (2007), 'An Introduction to Mentoring Principles, Processes and Strategies for Facilitating Mentoring Relationships at a Distance', http://www.usask.ca/gmcte/drupal/?q=resources (26 March 2014) [7] M. Marable and S. Raimond (2007) 'Teachers' Perceptions of What Was Most (and least) 
Supportive during their First Year of Teaching', Mentoring and Tutoring: Partnership in Learning 15(1), pp. 25-37.

[8] H. Hagger and D. McIntyre (2006), Learning Teaching from Teachers: Realising the Potential of School-based Teacher Education, Open University Press: Maidenhead.

[9] L. McCorkel and A. Tamar (1998), What Mentoring Does for Mentors: A Cross-cultural Perspective. European Journal of Teacher Education, 21(1), pp. 91-107.

[10] S. Perunka and R. Erkkilä (2012), 'Dialogical Mentoring in the Supervising of Student Teachers' Practice', International Journal for Cross-Disciplinary Subjects in Education 3(1), pp. 635-639.

[11] M. Letterman and B. Kimberly (2004), 'Dugan Team Teaching a Cross-Disciplinary Honors Course: Preparation and Development', College Teaching, 52(2), pp. 76-79.

[12] P. Hudson (2013). 'Mentoring as Professional Development: 'Growth for both' Mentor and Mentee', Professional Development in Education, 39(4), pp. 771783.

[13] I. Happo and P-L. Lehtelä (2011), 'What Concerns Student Teachers in Teaching?' Responsibility, Challenge and Support in Teachers' Lifelong Professional Development. György Mészáros and Iván Falus (Eds.), pp. 409-417.

http://www.atee1.org/uploads/atee_proceedings_2010.pdf (26 March 2014)

[14] M. Russel and J. Russel (2011), 'Mentoring Relationships: Cooperating Teachers' Perspectives on Mentoring Student Interns, The Professional Educator, 35(2), http://files.eric.ed.gov/fulltext/EJ988202.pdf (26 March 2014)

[15] P. Hudson, M. Usak and A. Savran-Gender (2010), 'Benchmarking Mentoring Practices: A case study in Turkey', Eurasia Journal of Mathematics, Science \& Technology Education, 6(4), pp. 245-252. 